\title{
Differences in sympathetic activity in normotensive, prehypertensive and hypertensive individuals
}

\author{
Arun Kumar. $\mathbf{B}^{1, *}$, Nirmala $\mathbf{N}^{2}$ \\ ${ }^{1}$ Assistant Professor, ${ }^{2}$ Former Professor, Dept. of Physiology, ${ }^{1}$ Saveetha Medical College \& Hospital Chennai, Tamil Nadu, \\ ${ }^{2}$ Sri Venkateshwara Medical College Hospital and Research Institute, Puducherry, India \\ *Corresponding Author: Arun Kumar. B \\ Email: ak30051987.ak@gmail.com
}

Received: $22^{\text {nd }}$ June, 2018

Accepted: $28^{\text {th }}$ June, 2018

\begin{abstract}
Introduction: Hypertension is a major health hazard which at a later stage might lead onto various cardiovascular complications. Prehypertension is a precursor of Stage-I hypertension. Thus, the present study was done to assess the sympathetic activity in normotensive, prehypertensive and hypertensive individuals.

Aims and Objectives: To compare the differences in sympathetic activity in normotensive, prehypertensive and hypertensive individuals.

Materials and Methods: The study was conducted on 30 normotensive, 30 prehypertensive and 30 hypertensive subjects. Autonomic function tests were recorded using the instrument Physiopac-PP4, Medicaid system, Chandigarh. The following sympathetic function tests were performed: 1. Blood pressure response to standing, 2. Cold pressor test, 3. Isometric handgrip test.

Results: Our findings on hypertensives showed that there is sympathetic dysfunction and on prehypertensives showed that there is sympathetic overactivity.

Conclusion: Autonomic function tests can be used as a routine screening test to predict the future risk of hypertension at an earlier stage and also for a better prognosis during treatment.
\end{abstract}

Keywords: Hypertensive, Prehypertensive, Autonomic function tests, Sympathetic dysfunction, Sympathetic overactivity.

\section{Introduction}

Hypertension is a chronic medical condition in which the blood pressure in the arteries is persistently elevated. This makes the heart to work harder than normal to circulate the blood through the vessels. The complications of the hypertension include coronary artery disease, stroke, heart failure, peripheral vascular disease, visual impairment and end-stage renal disease. But, the more prominent infliction of it is seen in the cardiovascular, renal and the central nervous system. ${ }^{1}$ The most important blood pressure (BP) regulatory mechanism is the neural control through autonomic nervous system. Sympathetic nervous system mainly controls the tone of the blood vessel whereas the heart rate is mainly influenced by the parasympathetic nervous system at resting state of the individual. ${ }^{2}$ There is normally a balance maintained between the sympathetic and parasympathetic nervous system in our body called as the sympathovagal balance. When this balance is lost, it might lead onto various diseases including hypertension. Prehypertension is a state of proneness to hypertension. Therefore, intervening at this stage can decrease the chance of becoming hypertensive and thus can improve the quality of life by avoiding the cardiovascular risks in future. ${ }^{3}$ As the autonomic function assessment is a simple way to diagnose the altered autonomic reactivity, the classical autonomic (sympathetic) function tests which are noninvasive tests have been chosen to evaluate the functional status of the sympathetic nervous system in normotensive, prehypertensive and hypertensive population to understand the degree of sympathovagal imbalance that can occur in the diseased and the disease prone population.

\section{Aims and Objectives}

To compare the differences in sympathetic activity in normotensive, prehypertensive and hypertensive individuals.

\section{Materials and Methods}

After obtaining clearance from the Institutional Ethical Committee of Sri Venkateshwara Medical College and Research Centre, 135 subjects were screened and among them, 30 normotensives, 30 prehypertensives and 30 hypertensive subjects were recruited for the study from Medicine OPD as well as the staffs of our college and hospital. According to JNC-7 classification, subjects in the age group 25-55 years of both the sexes with BP values of 100-119/60$79 \mathrm{~mm} \mathrm{Hg}$ were recruited as normotensives (group I), BP values of 120-139/80-89 mm $\mathrm{Hg}$ BP as prehypertensives (group II) and BP values of 140159/90-99 $\mathrm{mm} \mathrm{Hg}$ as Stage-I hypertensives (group III). ${ }^{4}$ Patients on any anti-hypertensive drugs, patients with cardiac diseases, persons with BMI > 30, alcoholics, smokers and diabetics were excluded from our study. Autonomic function tests (AFT) were carried out for the total study population $(\mathrm{n}=90)$ in our Physiology research lab, in the morning time (room temperature 
maintained at $20-25{ }^{\circ} \mathrm{C}$ ) using the instrument PHYSIOPAC-PP4, Medicaid system, Chandigarh. The following non-invasive cardiovascular sympathetic function tests were performed:

Blood Pressure Response to Standing (Orthostatic Test): The test was conducted after 5 minutes of supine rest. The subject was asked to attain standing posture within 3 seconds and recordings were taken. The blood pressure was recorded at baseline, immediately on standing and on $2 \mathrm{~min} \& 5 \mathrm{~min}$ after standing. The fall in systolic blood pressure (SBP) on immediate standing was calculated. ${ }^{5,6}$

Isometric Handgrip Test: The baseline blood pressure was recorded in the subject. He was then instructed to maintain a sustained hand grip on the dynamometer at $30 \%$ of his maximum voluntary contraction (MVC) for 2 minutes. The blood pressure was measured at the end of $2^{\text {nd }}$ minute and $5^{\text {th }}$ minute. Calculation of rise in diastolic blood pressure (DBP) was done using the formula DBP during the test- DBP at rest. ${ }^{5,6}$

Cold Pressor Test: The baseline BP was recorded. The cold water of $10^{\circ} \mathrm{C}$ was prepared in the Autonomic function test lab, Department of physiology. The patient immersed the hand in water up to the wrist for 1 minute. The blood pressure was taken at the end of $1 \mathrm{~min}, 2 \mathrm{~min}$ and $5 \mathrm{~min}$ of the procedure. Calculation of rise in diastolic BP was done using the formula diastolic BP during the test - baseline diastolic BP. ${ }^{5,6}$

\section{Statistical Analysis}

The data was analyzed using SPSS version 17. One-way ANOVA was used to compare the values between normotensive, prehypertensive and hypertensive groups. Post-hoc Tukey test was used for sub-group analysis.

\section{Results}

Table 1 shows the anthropometric measurements and the basal parameters of normotensive, prehypertensive and hypertensive subjects in our study.

The comparison of fall in SBP and DBP on orthostatic test (Table 2a, 2b), rise in SBP and DBP on cold pressor test (Table 3a, 3b) and rise in SBP and DBP on hand grip test (Table $4 \mathrm{a}, 4 \mathrm{~b}$ ) were done between the 3 groups.

Table 1: Anthropometric measurements and basal parameters of normotensive, prehypertensive and hypertensive subjects

\begin{tabular}{|l|c|c|c|}
\hline & Normotensive (NT) & Prehypertensive (PT) & Hypertensive (HT) \\
\hline Age (years) & $29.77 \pm 7.90$ & $31.77 \pm 6.49$ & $37.20 \pm 7.05$ \\
\hline Height $(\mathbf{c m})$ & $156.0 \pm 8.03$ & $158.4 \pm 8.5$ & $158.5 \pm 10.96$ \\
\hline Weight $(\mathbf{K g})$ & $56.48 \pm 6.67$ & $59.58 \pm 9.23$ & $63.9 \pm 9.37$ \\
\hline BMI $\left(\mathbf{k g} / \mathbf{m}^{2}\right)$ & $23.18 \pm 1.73$ & $23.64 \pm 2.20$ & $24.15 \pm 1.01$ \\
\hline Basal SBP $(\mathbf{m m}$ Hg) & $108.9 \pm 5.84$ & $128.5 \pm 4.47$ & $147.3 \pm 4.25$ \\
\hline Basal DBP $(\mathbf{m m}$ Hg) & $70.4 \pm 4.28$ & $84.27 \pm 2.55$ & $94.6 \pm 2.83$ \\
\hline
\end{tabular}

Table 2a: Comparison of fall in SBP and DBP on orthostatic test between normotensive, prehypertensive and hypertensive subjects

\begin{tabular}{|l|c|c|c|c|}
\hline & $\begin{array}{c}\text { Normotensive } \\
(\mathbf{N T})\end{array}$ & $\begin{array}{c}\text { Prehypertensive } \\
(\mathbf{P T})\end{array}$ & $\begin{array}{c}\text { Hypertensive } \\
(\mathbf{H T})\end{array}$ & P-value \\
\hline Fall in SBP $(\mathbf{m m ~ H g})$ & $10.33 \pm 2.88$ & $7.4 \pm 1.83$ & $19.33 \pm 4.31$ & $0.0001^{*}$ \\
\hline Fall in DBP (mm Hg) & $6.13 \pm 2.56$ & $6.2 \pm 1.76$ & $11.13 \pm 2.6$ & $0.0001^{*}$ \\
\hline
\end{tabular}

One-way ANOVA used; *p<0.05- significant

Table 2b: Comparison of fall in SBP and DBP on orthostatic test within groups

\begin{tabular}{|l|c|c|c|}
\hline & NT vs PT & NT vs HT & PT vs HT \\
\hline Fall in SBP & $\mathrm{p}=0.002^{*}$ & $\mathrm{p}=0.0001^{*}$ & $\mathrm{p}=0.0001^{*}$ \\
\hline Fall in DBP & $\mathrm{p}=0.993$ & $\mathrm{p}=0.0001^{*}$ & $\mathrm{p}=0.0001^{*}$ \\
\hline
\end{tabular}

Post-hoc Tukey test used; $* \mathrm{p}<0.05$ - significant

Table 3a: Comparison of rise in SBP and DBP on cold pressor test between normotensive, prehypertensive and hypertensive subjects

\begin{tabular}{|l|c|c|c|c|}
\hline & $\begin{array}{c}\text { Normotensive } \\
(\mathbf{N T})\end{array}$ & $\begin{array}{c}\text { Prehypertensive } \\
(\mathbf{P T})\end{array}$ & $\begin{array}{c}\text { Hypertensive } \\
(\text { HT })\end{array}$ & P-value \\
\hline Rise in SBP (mm Hg) & $20.27 \pm 5.5$ & $20.33 \pm 4.27$ & $10.7 \pm 5.47$ & $0.0001^{*}$ \\
\hline Rise in DBP (mm Hg) & $12.53 \pm 2.09$ & $16.47 \pm 1.87$ & $7.53 \pm 2.71$ & $0.0001^{*}$ \\
\hline
\end{tabular}

One-way ANOVA used; *p<0.05- significant 
Table 3b: Comparison of rise in SBP and DBP on cold pressor test within groups

\begin{tabular}{|l|c|c|c|}
\hline & NT vs PT & NT vs HT & PT vs HT \\
\hline Rise in SBP & $\mathrm{p}=0.993$ & $\mathrm{p}=0.0001^{*}$ & $\mathrm{p}=0.0001^{*}$ \\
\hline Rise in DBP & $\mathrm{p}=0.0001^{*}$ & $\mathrm{p}=0.0001^{*}$ & $\mathrm{p}=0.0001^{*}$ \\
\hline
\end{tabular}

Post-hoc Tukey test used; *p<0.05- significant

Table 4a: Comparison of rise in SBP and DBP on hand grip test between normotensive, prehypertensive and hypertensive subjects

\begin{tabular}{|l|c|c|c|c|}
\hline & $\begin{array}{c}\text { Normotensive } \\
(\mathbf{N T})\end{array}$ & $\begin{array}{c}\text { Prehypertensive } \\
(\mathbf{P T})\end{array}$ & $\begin{array}{c}\text { Hypertensive } \\
(\mathbf{H T})\end{array}$ & P-value \\
\hline Rise in SBP (mm Hg) & $22.6 \pm 5.8$ & $23 \pm 5.21$ & $12.27 \pm 4.44$ & $0.0001 *$ \\
\hline Rise in DBP (mm Hg) & $15.87 \pm 2.82$ & $20.47 \pm 3.39$ & $10.87 \pm 3.47$ & $0.0001 *$ \\
\hline
\end{tabular}

One-way ANOVA used; *p<0.05- significant

Table 4b: Comparison of rise in SBP and DBP on hand grip test within groups

\begin{tabular}{|l|c|c|c|}
\hline & NT vs PT & NT vs HT & PT vs HT \\
\hline Rise in SBP & $\mathrm{p}=0.999$ & $\mathrm{p}=0.0001^{*}$ & $\mathrm{p}=0.0001^{*}$ \\
\hline Rise in DBP & $\mathrm{p}=0.0001^{*}$ & $\mathrm{p}=0.0001^{*}$ & $\mathrm{p}=0.0001^{*}$ \\
\hline
\end{tabular}

Post-hoc Tukey test used;* $\mathrm{p}<0.05$ - significant

\section{Discussion}

Orthostatic Test: Orthostatic test showed that there was a significant difference in fall in SBP and DBP in all the 3 groups. Among the groups, hypertensives had the highest fall in SBP and DBP significantly on immediate standing. Prehypertensives had the least fall in SBP significantly. (Table 2a, 2b)

James MA et al. suggested that significant fall in $\mathrm{BP}$ in hypertensive subjects is mainly attributed to the diminished baroreflex sensitivity. ${ }^{7}$ Another study showed that SBP fall in hypertensive patients on standing is a good indicator of sluggish baroreflex mechanism and consequently of autonomic dysfunction in hypertensives. ${ }^{8}$ Pal GK et al. observed the similar results in case of prehypertensive subjects and suggested that reduced BP fall in prehypertensives is due to sympathetic hyperactivity occurring in them. ${ }^{9}$

Cold Pressor Test: On cold pressor test, there was a significant rise in SBP and DBP in normotensives. Rise in DBP was significantly higher in prehypertensives. In hypertensives, the rise in SBP and DBP was significantly lower compared to the other groups. (Table 3a, 3b)

Deepak KK, Ewing et al. explained that only a mild or no increase in DBP on cold pressor test is considered as an abnormal response and is thus suggestive of sympathetic dysfunction. ${ }^{5,10}$ Khaliq Farah et al. showed similar results of significant rise in SBP and DBP in prehypertensive subjects on cold pressor test and explained that this sympathetic hyperactivity occurring in prehypertensives might be predisposing to the development of hypertension at a later point of time. ${ }^{11}$

Hand Grip Test: On hand grip test, prehypertensives showed a significantly higher rise in DBP than the normotensives. But, there was no significant rise in SBP in prehypertensives when compared to normotensives. In hypertensives, the rise in SBP and DBP was significantly lower compared to the other two groups. (Table 4a, 4b)

Vaishali et al., Ewing et al. showed the similar results of reduced rise in SBP and DBP on hand grip test in hypertensives and explained that it might be due to sympathetic autonomic dysfunction occurring in hypertensives. ${ }^{12}$ Higher rise in SBP and DBP on hand grip test in prehypertensives were shown by Pal GK et al. and explained that this rise might be due to increased sympathetic activity occurring in prehypertensive individuals. $^{9}$

All our findings showed that there is sympathetic overactivity in prehypertensives and sympathetic dysfunction in hypertensive individuals. The pathophysiology of prehypertension and hypertension is mainly attributed to the alteration in their sympathetic activity. ${ }^{13}$ There is primarily an evidence of increased plasma norepinephrine in essential hypertension. ${ }^{14}$ Activation of the sympathetic nervous system might also be due to increased circulating angiotensin-II and endothelin levels. ${ }^{15}$ Another possibility is due to impairment of baroreceptor reflex activity as a result of its resetting towards the higher BP values. ${ }^{16}$ The reason for sympathetic dysfunction might be due to ischemia of the small arteries and arterioles causing demyelination of the sympathetic nerves as a result of long-standing hypertension. ${ }^{17}$

\section{Conclusion}

Autonomic function tests can be used as a routine screening test to predict the future risk of hypertension at an earlier stage and also for a better prognosis during treatment. Early detection of proneness to hypertension might help an individual to lead a healthy life by following certain life style modifications like diet restriction, exercise and yoga. 


\section{References}

1. Faculty of Public Health/Hypertension - the "Silent killer".

Available from: http:// www.fph.org.uk/uploads/brhypertension.pdf [Last accessed on 2017 June 25]

2. Barrett KE, Barman SM, Boitano S, Brooks H. Cardiovascular regulatory mechanisms. Ganong's Review of Medical Physiology 2012. 24 ${ }^{\text {th }}$ Edition, Mcgraw-hill Education; Chapter 33:555-568.

3. Nadgouda VG. Prehypertension. Medicine update. 2010; 20: $400-403$

4. Chobanian AV, Bakris GL, Black HR, Cushman WC, Green LA, Izzo JL, et al. Seventh report of the Joint National Committee on Prevention, Detection, Evaluation and Treatment of High Blood Pressure. Hypertension. 2003;42(6):1206-1252

5. Deepak KK. Cardiovascular autonomic functions testingprinciples and methods. Autonomic function lab. 2006;1:1-12

6. Campbell IW, Ewing DJ, Clarke BF. Tests of cardiovascular reflex function in diabetic autonomic neuropathy. Hormone and metabolic research supplement series. 1980;9:61-67

7. James MA, Robinson TG, Potter JF. The effect of systemic blood pressure on cardio-vascular reflexes in elderly subjects. Clinical Physiology. 2001;21(1):67-76

8. Bakkali ME, Benjelloum H, Rkain H, Coghlan L, Leila E, Souad A, et al. A cross-sectional study evaluating orthostatic hypotension in normotensive and hypertensive patients with diabetes mellitus. Journal of Cardiovascular Medicine. 2013;1(1):3-7.

9. Pal GK, Pal P, Nanda N, Lalitha V, Dutta TK, Adithan C. Sympathovagal Imbalance in Prehypertensive Offspring of Two Parents versus One Parent Hypertensive. International Journal of Hypertension. 2011;20:163-170.

10. Ewing DJ, Clarke BF. Diagnosis and management of autonomic neuropathy. BMJ. 1982;285:916-918.
11. Farah K, Keshav G, Pawan S. Autonomic reactivity to cold pressor test in prehypertensive and hypertensive medical students. Indian journal of Physiology and Pharmacology. 2011;55(3):246-252

12. Vaishali VP, Vinod VK, Hiremath DA, Jyothi JP. Assessment of cardiovascular sympathetic function tests in hypertensive patients. Medica Innovatica. 2012;1(2):39-42.

13. Scott Gilbert. Pathophysiology of Hypertension. Tufts University, School of Medicine. Available from: http://www.ocw.tufts.edu/data/33/498002.pdf [Last accessed on 2018 March 25]

14. Mancia G, Grassi G, Giannattasio C, Seravalle G. Sympathetic activation in the pathogenesis of hypertension and progression of organ damage. Hypertension. 1999;34(4):724-728

15. Oparil S, Zaman MA, Calhoun DA. Pathogenesis of hypertension. Annals of Internal Medicine. 2003;139(9):761-776.

16. Matthews KA, Woodall KL, Allen MT. Cardiovascular reactivity to stress predicts future blood pressure status. $J$ Hypertension. 1993;22:479-485.

17. Peter Kempler. Autonomic neuropathy: a marker of cardiovascular risk. Br J Diabetes Vasc Dis. 2003;3(2):84-90.

How to cite this article: Kumar A. B, Nirmala N. Differences in sympathetic activity in normotensive, prehypertensive and hypertensive individuals. Indian J Clin Anat Physiol. 2018;5(4):430-433. 